\title{
COMPUTER TECHNOLOGY Parametric interactions in EEG period analysis
}

\author{
LARRY ROUSE and PAUL LANDRESSE \\ Spectrum Research and Development, Fresno, California 93778
}

\begin{abstract}
Off-line statistical analysis of computer-generated EEG period distribution parameters indicates the presence of important interactions within the traditional frequency bands and that confounded psychological variables null out highly significant results.
\end{abstract}

Period analysis has been unequivocally effective in EEG research (e.g., Creutzfeldt, Grunewald, Simonova, \& Schmitz, 1969; Rouse, Peterson, \& Shapiro, 1975; Sharp, Smith, \& Surwillo, 1975; Surwillo, 1975). With respect to percent activity within the traditional EEG frequency bands, Beatty and Figueroa (1974) reported a .79 correlation between period and Fourier analysis results. They suggested that the simpler period-analytic methods be used to estimate frequency-band percenttime measures.

Notwithstanding certain theoretical restrictions, Fourier analysis continues to provide meaningful information about the EEG (Dumeruth \& Keller, 1973). In contrast to most applications that use the power spectrum, Sayer (1974) showed that the auditory evoked potential is generated by a change in the cosine series (phase spectrum) with no discernible change in the power spectrum. To date, no one has solved the persistent problem of within-epoch phase shifts that degrade estimates of nonstationary components contributing to the power spectrum. Hoovey, Heinemann, and Creutzfeldt (1972) showed that phase shifts of the dominant occipital alpha rhythm occur frequently and both abruptly and gradually. When the Fourier series is used to represent nonrecurring functions (like the EEG is to a large extent), it is suggested that the analysis be done and remain valid only over the half-cycle interval between zero crossings (Richmond, 1972). In this case, only the sine or cosine series is computed, depending on the type of function. If this approach is taken, the second step or calculation of the fundamental is equivalent to half-wave period analysis.

Period analysis has normally been carried out with the assumption that spectral parameters (e.g., variance) are linearly related when computed on the basis of different data ranges (e.g., an $8-$ to $12 \cdot \mathrm{Hz}$ bandpass compared to one of $9-11 \mathrm{~Hz}$ ). This assumption does

This research was supported in part by the Califomia State University, Fresno, California, and the Valley Medical Foundation, Fresno, California. Reprint requests should be sent to L. O. Rouse, P.O. Box 12576, Fresno, California 93778. The second author is currently with Burroughs Corporation. not hold for the EEG. The analysis is further complicated by confounded psychological variables (e.g., arousal level and subjective affect) that alter the spectral interactions. The following example of this problem is based upon four consecutive 3 -min cumulative period distributions taken from 24 human subjects, 12 male and 12 female (EEG $\mathrm{C}_{1}-\mathbf{A}_{2}, \mathbf{A}_{1}$ ground). Period analysis was based upon half-wave measurements of the full-wave rectified EEG (amplitude half down at 7 and $14 \mathrm{~Hz}$ ) (Rouse, 1975). Spectral parameters computed on the basis of successively inclusive bandpass limits were compiled by a CDC 3150 computer according to the format shown in Table 1 .

Table 1

Program Description

Constraints: The maximum number of trials for each subject is 10 and the maximum number of subjects is 999 . The bandwidth is restricted to $8 \mathrm{~Hz}$ and must be in $.5-\mathrm{Hz}$ increments (this example uses the range 7-14 $\mathrm{Hz}$ ).

Data preparation: Each data card for each subject must follow this pattern.

\section{Column Description}

1-3 Three-digit subject number that must be right justified (i.e., 001, 002, 003, . . , 010, 011, ..., 999).

4-5 Two-digit card number that must also be right justified. This number is used along with the subject number to sort the data cards into proper order should the deck be dropped.

6 The code (1-9) for Condition A.

The code (1-9) for Condition B.

$\begin{aligned} 8 & \text { The code }(1-9) \text { for Condition C. } \\ 9 & \text { Raw data in the following order }\end{aligned}$

9-80 Raw data in the following order: Bin 1-Trial 1 Bin 2-Trial 1, Bin 2-Trial 2 . . Bin 2-Trial N . . Bin 15-Trial N. Use as many cards as necessary for each subject.

Parameter cards: Card I (all fields right justified)

Column Description

1-5 The number of trials for this analysis.

6-10 Number of subjects.

11-15 The number of raw data cards per subject

16-20 The number of variable format cards.

21-25 Any number punched in this field will cause the program to punch the results of all calculations into cards. 
Table 1 Continued

Card II

\begin{tabular}{cl} 
Column & \multicolumn{2}{c}{ Description } \\
$1-3$ & Frequency designation of the first bin. \\
$4-6$ & Frequency designation of the second bin.
\end{tabular}

43-45 Frequency designation of the 15 th bin.

All frequency bins are three digits in length and have an implied decimal point botween the second and third digit (e.g., 070 , $075, \ldots, 135,140$ ).

Card III Variable format card(s).

Column

$1-80$
Description

This card describes the raw data to the program. All FORTRAN IV conventions apply. The card(s) must begin with a left parenthesis on the first card and end with a right parenthesis on the last card. Furthermore, it is mandatory that all variables be specified in floating point mode.

When describing the data to this program, the subject number and Codes $A, B$, and $C$ will be specified as appearing on the first card (for the subject) only. The card numbers must always be ignored. For data with three cards per subject, four trials and 15 bins, the variable format for the first stage of analysis is: (F3.0, 2X, 3F 1.0, 24F3.0/8X, 24F3.0/8X, 12F3.0)

Sample deck setup: \$JOB, ; Binary program deck: \$RUN ; Card I ; Card II ; Card III ; Data Deck ; 87 End of File ; \$EOJ Card output: All output cards will appear as follows:

Colum
$1-3$
$4-5$

$6-8$
$9-78$

Description

1-3 Subject number.

4-5 Card number. This number will begin at 1 plus the number of input cards specified in Parameter Card I in Columns 11-15.

6-8 The codes for Conditions $A, B$, and C.

9-78 Up to 10 fields ( 7 columns/field) of data computed by this program. Each field represents the results from one trial.

The cards will be output in the following order: Summed counts in $7-$ to $14-\mathrm{Hz}$ bins, $8-$ to $12-\mathrm{Hz}$ bins, and $9-$ to $11-\mathrm{Hz}$ bins; mean frequency $(\mathrm{Hz})$ in ibid; standard deviation $(\mathrm{Hz})$ ibid; skewedness $(\mathrm{Hz})$ counts; kurtosis $(\mathrm{Hz})$ ibid; ratios of $10-\mathrm{Hz}$ counts $/ 9$ - to $11-\mathrm{Hz}$ counts, $10-\mathrm{Hz}$ counts/8- to $12-\mathrm{Hz}$ counts, $10-\mathrm{Hz}$ counts/7- to $14-\mathrm{Hz}$ counts, $9-$ to $11-\mathrm{Hz}$ counts $/ 8-$ to $12-\mathrm{Hz}$ counts, $9-$ to $11-\mathrm{Hz}$ counts/7- to $14-\mathrm{Hz}$ counts, 8 - to $12-\mathrm{Hz}$ counts $/ 7-$ to $14-\mathrm{Hz}$ counts; differences of $9-$ to $11-\mathrm{Hz}$ counts minus $10-\mathrm{Hz}$ counts, $8-$ to $12-\mathrm{Hz}$ counts minus $9-$ to $11-\mathrm{Hz}$ counts, $7-$ to $14-\mathrm{Hz}$ counts minus $8-$ to $12-\mathrm{Hz}$ counts.

These calculations may be performed for any $8-\mathrm{Hz}$ (or eight frequency class intervals) range in $.5-\mathrm{Hz}$ (or .5-interval) increments by changing parameter Card II and supplying the appropriate data. This example has used the range of 7-14 Hz. All changes will be proportional, however. If a range of $6-13 \mathrm{~Hz}$ is used, for example, the following occurs: All references to $7-14 \mathrm{~Hz}$ become $6-13 \mathrm{~Hz} ; 8-12 \mathrm{~Hz}$ becomes $7-11 \mathrm{~Hz} ; 9-11 \mathrm{~Hz}$ becomes 8-10 Hz, and $10 \mathrm{~Hz}$ becomes $9 \mathrm{~Hz}$.

As a means of conserving space on the output cards, all fields requiring a decimal point have been multiplied by an appropriate scaler to eliminate the decimal. This method provides the user with the equivalent of an implied decimal, the position of which can be determined from the printed report.

For subsequent analysis on the output deck, the variable format (including the input data deck as front running cards segregated for each subject) is as follows:

(5X,3F1.0,24F3.0/8X.24F3.0/8X,12F3.0,3(/8X,4F7.0),12(/8X, 4F7.2),6(8X,4F7.3), 3(/8X,4F7.0))
Table 2 is an example of the data matrix printout for one subject. These distribution parameters are generated on the basis of four serial 3-min period spectra. The original bin counts are shown in Table 3. Results with this approach have been meaningful and unique in some cases. For example, during a meditation including EEG alpha biofeedback, subjects who report the absence of drowsiness show an increase in counts in the $7 \cdot$ to $14 \mathrm{~Hz}$, 8- to $12-\mathrm{Hz}$, and 9- to $11-\mathrm{Hz}$ ranges, while subjects who report drowsiness show significant increases in the 7 . to $14-\mathrm{Hz}$ and 9. to $11-\mathrm{Hz}$ ranges only after feedback is terminated and a continuous decrease in the $8-$ to $12-\mathrm{Hz}$ range during and after feedback. Spectral dynamics indicate that nondrowsing subjects show markedly better midrange entrainment $(9.11 \mathrm{~Hz})$, while not differing from the drowsing subjects in terms of mean frequency, which uniformly decreases for all subjects. Drowsers also show a marked transfer of counts from the $12-\mathrm{Hz}$ to the $7.5-\mathrm{Hz}$ bin. Drowser variance differs (is greater) from the nondrowsers only when computed on the basis of the $7-$ to $14 \mathrm{~Hz}$ and $8-$ to $12 \mathrm{~Hz}$ count ranges. Nondrowsers show an exclusive decrease in variance and kurtosis parameters computed for the 8to $12-\mathrm{Hz}$ range, an exclusive increase in $10-\mathrm{Hz}$ counts,

Table 2

\begin{tabular}{|c|c|c|c|c|}
\hline & \multicolumn{4}{|c|}{ Time Block } \\
\hline & 1 & 2 & 3 & 4 \\
\hline $\begin{array}{l}\text { Summed Counts in } \\
10 \mathrm{~Hz} \text { Bin } \\
7-14 \mathrm{~Hz} \text { Bins } \\
8-12 \mathrm{~Hz} \text { Bins } \\
9-11 \mathrm{~Hz} \text { Bins }\end{array}$ & $\begin{array}{r}464 \\
3,335 \\
2,792 \\
1,953\end{array}$ & $\begin{array}{r}705 \\
3,694 \\
3,298 \\
2,575\end{array}$ & $\begin{array}{r}739 \\
3,440 \\
3,144 \\
2,563\end{array}$ & $\begin{array}{r}718 \\
3,447 \\
3,143 \\
2,572\end{array}$ \\
\hline $\begin{array}{l}\text { Mean Frequency in } \\
\text { 7-14 Hz Bins } \\
\text { 8-12 Hz Bins } \\
9-11 \mathrm{~Hz} \text { Bins }\end{array}$ & $\begin{array}{l}10.59 \\
10.23 \\
10.13\end{array}$ & $\begin{array}{l}10.21 \\
10.07 \\
10.01\end{array}$ & $\begin{array}{r}10.14 \\
10.02 \\
9.98\end{array}$ & $\begin{array}{r}10.12 \\
9.97 \\
9.96\end{array}$ \\
\hline $\begin{array}{l}\text { Standard Deviation in } \\
7-14 \mathrm{~Hz} \text { Bins } \\
8-12 \mathrm{~Hz} \text { Bins } \\
9-11 \mathrm{~Hz} \text { Bins }\end{array}$ & $\begin{array}{r}1.48 \\
1.08 \\
.65\end{array}$ & $\begin{array}{r}1.40 \\
1.06 \\
.73\end{array}$ & $\begin{array}{r}1.26 \\
.98 \\
.70\end{array}$ & $\begin{array}{r}1.26 \\
.97 \\
.71\end{array}$ \\
\hline $\begin{array}{l}\text { Skewedness in } \\
7-14 \mathrm{~Hz} \text { Bins } \\
\text { 8-12 Hz Bins } \\
9-11 \mathrm{~Hz} \text { Bins }\end{array}$ & $\begin{array}{r}.83 \\
-.66 \\
-.39\end{array}$ & $\begin{array}{r}.98 \\
-.12 \\
-.23\end{array}$ & $\begin{array}{l}.98 \\
.40 \\
.25\end{array}$ & $\begin{array}{r}1.02 \\
.41 \\
.28\end{array}$ \\
\hline $\begin{array}{l}\text { Kurtosis in } \\
7-14 \mathrm{~Hz} \text { Bins } \\
8-12 \mathrm{~Hz} \text { Bins } \\
9-11 \mathrm{~Hz} \text { Bins }\end{array}$ & $\begin{array}{r}1.88 \\
1.33 \\
.76\end{array}$ & $\begin{array}{r}1.84 \\
1.28 \\
.81\end{array}$ & $\begin{array}{r}1.75 \\
1.22 \\
.79\end{array}$ & $\begin{array}{r}1.74 \\
1.21 \\
.79\end{array}$ \\
\hline $\begin{array}{l}\text { Count Ratios } \\
10 \mathrm{~Hz} \text { to } 9-11 \mathrm{~Hz} \\
10 \mathrm{~Hz} \text { to } 8-12 \mathrm{~Hz} \\
10 \mathrm{~Hz} \text { to } 7-14 \mathrm{~Hz} \\
9-11 \mathrm{~Hz} \text { to } 8-12 \mathrm{~Hz} \\
9-11 \mathrm{~Hz} \text { to } 7-14 \mathrm{~Hz} \\
8-12 \mathrm{~Hz} \text { to } 7-14 \mathrm{~Hz}\end{array}$ & $\begin{array}{l}.238 \\
.166 \\
.129 \\
.699 \\
.586 \\
.837\end{array}$ & $\begin{array}{l}.274 \\
.214 \\
.191 \\
.781 \\
.697 \\
.893\end{array}$ & $\begin{array}{l}.288 \\
.235 \\
.215 \\
.815 \\
.745 \\
.914\end{array}$ & $\begin{array}{l}.279 \\
.228 \\
.208 \\
.818 \\
.746 \\
.912\end{array}$ \\
\hline $\begin{array}{l}\text { Count Differences } \\
9-11 \mathrm{~Hz} \text { minus } 10 \mathrm{~Hz} \\
8-12 \mathrm{~Hz} \text { minus } 9-11 \mathrm{~Hz} \\
7-14 \mathrm{~Hz} \text { minus } 8-12 \mathrm{~Hz}\end{array}$ & $\begin{array}{r}1,489 \\
839 \\
543 \\
\end{array}$ & $\begin{array}{r}1,870 \\
723 \\
396 \\
\end{array}$ & $\begin{array}{r}1,824 \\
581 \\
296\end{array}$ & $\begin{array}{r}1,854 \\
571 \\
304 \\
\end{array}$ \\
\hline
\end{tabular}


Table 3

Original Bin Counts

\begin{tabular}{ccccccccccccccccccccccccc}
\hline & 1 & 2 & 3 & 4 & 1 & 2 & 3 & 4 & 1 & 2 & 3 & 4 & 1 & 2 & 3 & 4 & 1 & 2 & 3 & 4 & 1 & 2 & 3 & 4 \\
\hline 0130121 & 009 & 031 & 032 & 023 & 055 & 087 & 052 & 050 & 129 & 111 & 095 & 107 & 174 & 193 & 164 & 172 & 224 & 370 & 351 & 385 & 369 & 539 & 602 & 612 \\
0130221 & 464 & 705 & 739 & 718 & 482 & 579 & 537 & 548 & 424 & 382 & 334 & 309 & 294 & 254 & 196 & 183 & 242 & 165 & 126 & 109 & 172 & 099 & 085 & 103 \\
0130321 & 140 & 084 & 058 & 055 & 103 & 053 & 029 & 041 & 064 & 042 & 040 & 032 & & & & & & & & &
\end{tabular}

Note-The first entry in each line indicates the three-digit subject number (Digits 1-3), the two-digit card number (Digits 45), and the code for Condition $A, B$, or $C$ (Digits 6-7). The remaining entries indicate the bin counts for frequency class intervals increasing in $.5 . \mathrm{Hz}$ increments (i.e., starting with Line 1, Columns 1.4 refer to $7.0 \mathrm{~Hz}$, Columns 5.8 refer to $7.5 \mathrm{~Hz}$, continuing in left-to-right order to Line 3, Columns 9-12, which refer to $14.0 \mathrm{~Hz}$.

more 9.5- and $10-\mathrm{Hz}$ counts, and less $12-$ to $14-\mathrm{Hz}$ counts, both within their own distributions over time and when compared to the drowsers. A statistical analysis that confounds data from the drowsers and nondrowsers shows no significant change in variance within any of the three ranges used here. It is not unreasonable to expect that other range calculations might produce additional information. Analysis of the intercorrelation matrix patterns indicated that the nondrowsers show a very general and markedly high degree of covariance, while drowsers are very poor in this respect $(\mathrm{p}<.001)$.

It is important to note that these differences are a function of the experimental setting. The psychological dimension of affect was orthogonal to arousal on every measure except kurtosis, which was the only parameter to differentiate positive from negative affect when computed on the basis of the $8-$ to $12-\mathrm{Hz}$ range (there was a trend for a difference occurring for the variance measure for this same range). Subjects who report a preference for the feedback tone produce more peaked distributions; that is, they are leptokurtotic (a lower kurtosis index). These and other results confirm the hypothesis that arousal level and affective state can both influence the EEG but in different ways. The results also suggest that a single parameter analysis of EEG (e.g., percent time alpha) is highly limited, and that confounded psychological variables can obscure important results. A complete program listing is given in the Appendix.

\section{APPENDIX}

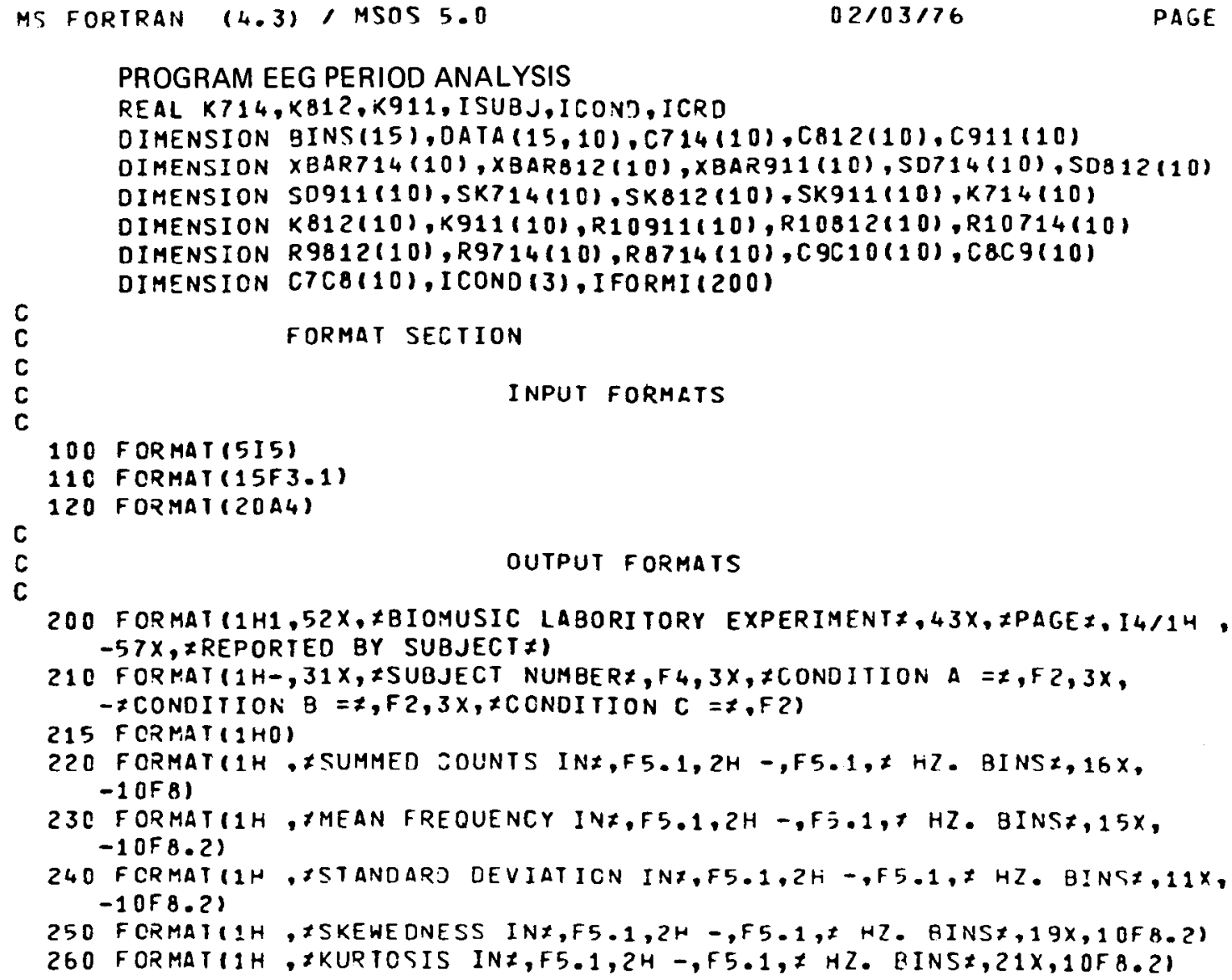

PROGRAM EEG PERIOD ANALYSIS

REAL K714,K812,K911, ISUBJ,ICONT, ICRD

DIMENSION GINS(15),DATA $(15,10), C 714(10), C 812(10), C 911(10)$

DIMENSION XBAR714(10), XBARB12(10), XBAR911(10),SD714(10),SDB12(10)

DIMENSION SO911(10),SK714(10),SK812(10),SK911(10),K714(10)

DIMENSION K812(10),K911(10),R10911(10),R10312(10),R10714(10)

DIMENSION R9812(10),R9714(10),R8714(10),C9C10(10), C8C9(10)

DIMENSION C7CB(10), ICOND(3), IFORMI (200)

C

C

C

C

C

100 FORMAT (5I5)

110 FORMAT (15F3.1)

C

120 FORMAT (20A4)

C

C 


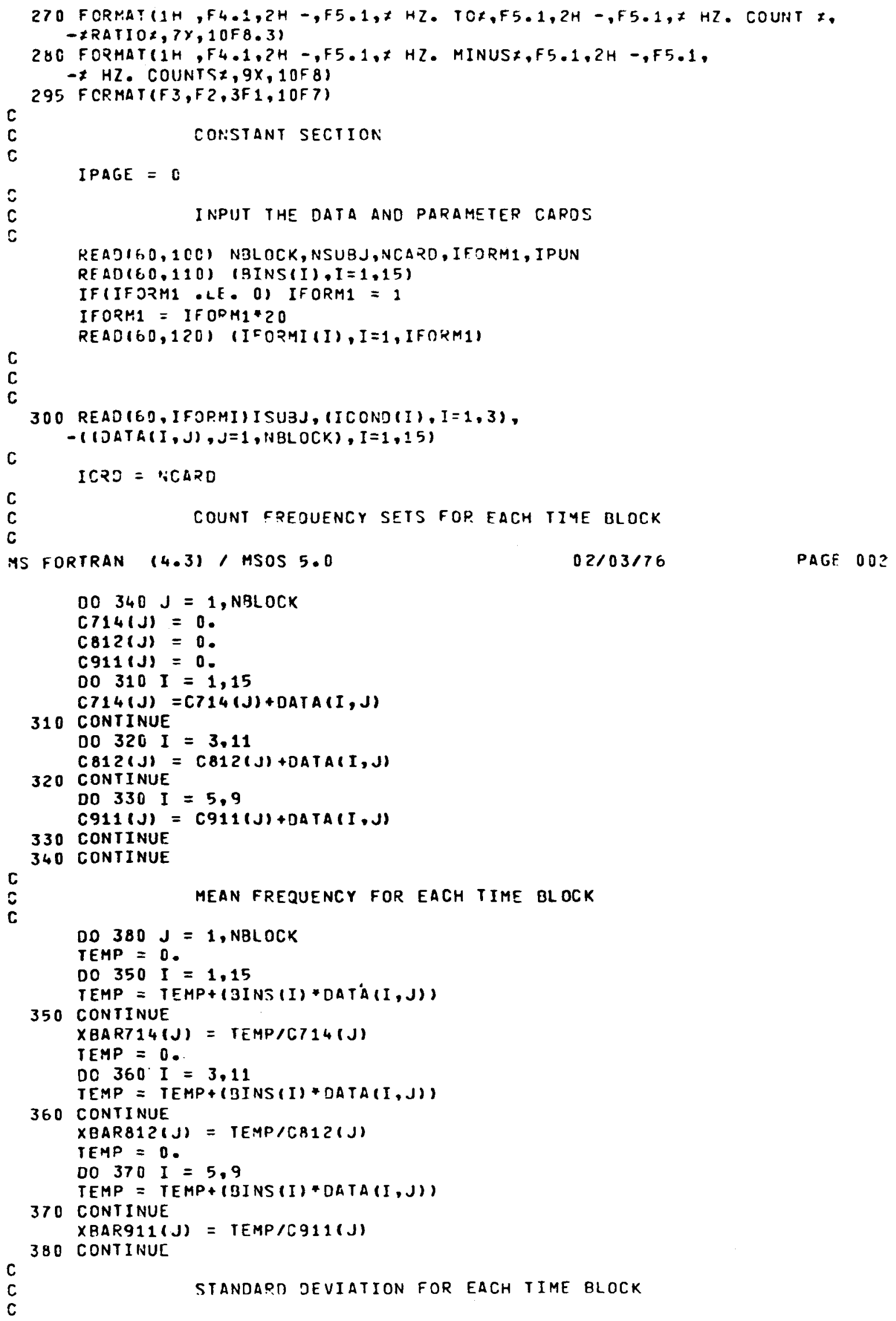




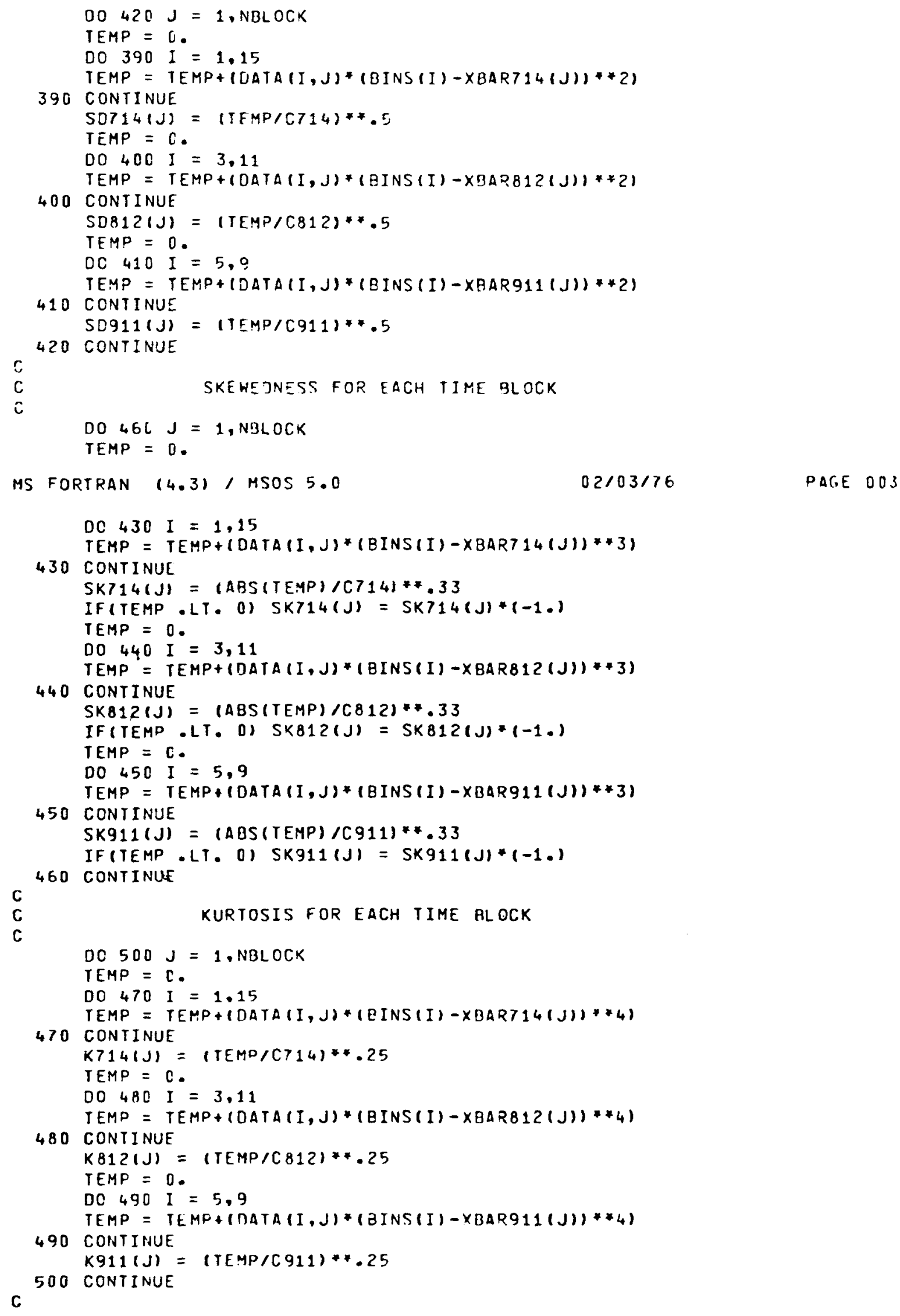

DC $430 I=1,15$

TEMP $=$ TEMP+(DATA $(I, J) *(B I N S(I)-\times B A R 714(J)) * 3)$

430 CONTINUE

SKT14(J) = (ABS (TEMP) /C714)**.33

IF (TEMP . LT. O) SK714(J) $=5 K 714(\mathrm{~J}) *(-1$.

TEMP $=0$.

DO $440 I=3,11$

$\operatorname{TEMP}=\operatorname{TEMP+(DATA}(I, J) *(B I N S(I)-X B A R B 12(J)) * 3)$

440 CONTINUE

SKB12(J) $=(A B S(T E M P) / C 812) * * .33$

IF (TEMP . LT. D) $S K 812(\mathrm{~J})=S K 812(\mathrm{~J}) *(-1$.

TEMP $=$ C.

DO $450 I=5,9$

TEMP $=$ TEMP+(DATA $(I, J) *(B I N S(I)-X B A R 911(J)) * * 3)$

450 CONTINUE

SK911(J) $=(A B S(T E M P) / C 911) * * 33$

C

IF (TEMP. LT. O) SK911(J) $=\operatorname{SK} 911(J) *(-1$.

460 CONTINUE

C

KURTOSIS FOR EACH TIME RLOCK

DO $500 \mathrm{~J}=1$, NBLOCK

TEMP $=\mathrm{C}$.

DO $470 I=1,15$

TEMP = TEMP+ (DATA $(I, J) *(E I N S(I)-X B A R 714(J)) * 4)$

470 CONTINUE

$K 714(J)=(T E M D / C 714)^{* * .25}$

TEMP $=0$.

DO 480 I $=3,11$

TEMP $=$ TEMP+(DATA $(I, J) *(B I N S(I)-X B A R 812(J)) * * 4)$

480 CONTINUE

$K B 12(J)=($ TEMP/C 812)**.25

TEMP $=0$.

DO 490 I $=5.9$

TEMP $=$ TEMP+ (NATA $(I, J) *(B I N S(I)-X B A R 911(J)) * * 4)$

490 CONTINUE

K911(J) $=($ TEMP/C911)**.25

c

500 CONTINUE 
C PATIOS FOR EACH TIME BLOCK

C

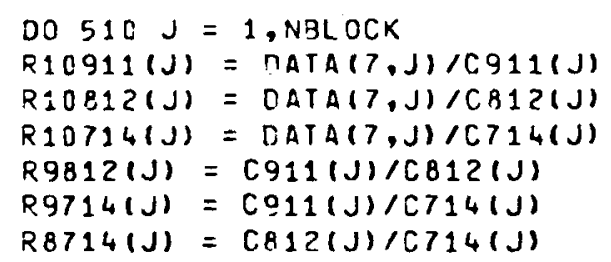

C

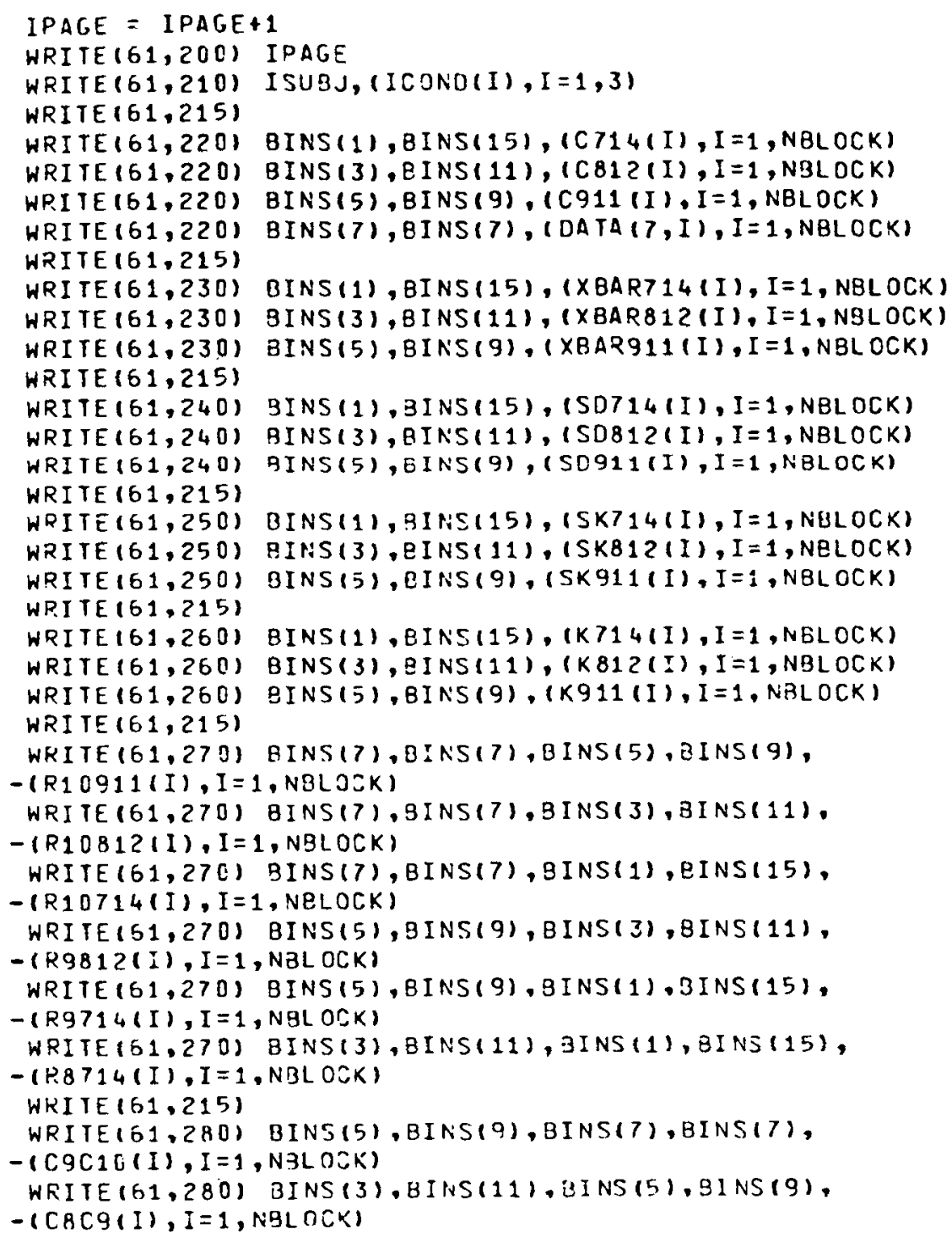


C
C
C
C
C

$M S$

WPITE (61,280) 2INS(1), FIRS(15), PINS(3), AINS(11),

$-(C 7 C 8(I), I=1$, NPLOCK)

OUTPUT TO CAPOS

IF PROCESSING OF RAW DATA EY ANOTMEF PROGRAM IS

DESIRED, THE INPUT FROM THIS PROGRAM SHOULD $3 E$ USED.

IFIIPUN ES. O) GO IO 600

DO $530 \mathrm{~J}=1$, NBL OCK

XBAR714(J) $=$ XIAR714(J)*100

$X E A P 812(\mathrm{~J})=$ YEAPR12(J)*100

$X 3 A P 911(\mathrm{~J})=X 3 A P 911(\mathrm{~J}) * 100$

$50714(\mathrm{~J})=50^{7} 14(\mathrm{~J}) * 100$

$5 D 812(J)=5 n 312(\mathrm{~J}) \cdot 100$

SO911(J) = SD911(J)*10C

FORTRAN (4.3) $/$ MSOS 5.0

$S K 714(J)=S K 714(J)=100$

SKB12(J) $=5 K 812(J) * 100$

$\operatorname{SK911(J)=SK911(J)*100~}$

$K 714(J)=K 714(J) * 100$

$K 812(J)=K 812(J) * 100$

$K 911(J)=K 911(J) * 100$

$R 10911(\mathrm{~J})=R 10911(\mathrm{~J}) \neq 1000$

$R 10812(\mathrm{~J})=R 10812(\mathrm{~J}) * 1000$

$R 10714(J)=P .10714(J) * 1000$

$R 9812(\mathrm{~J})=R 9812(\mathrm{~J}) * 1000$

$R 9714(\mathrm{~J})=R 9714(\mathrm{~J}) * 1000$

$R B 714(J)=R B 714(J) * 1000$

530 CONTINUE

ICRO = ICRD+1

WRI TE $(62,295)$ ISUBJ, ICRD, (ICCNJ(I),I =1,3), (C714 (J), J=1, NEL OCK)

$I C R D=I C R D+1$

WRITE $(62,295)$ ISUB J, ICRD, (ICOND (I), I = 1,3), (C812(J), J=1, NBL OCK)

$I C R D=I C R N+1$

WRITE (62, 295) ISUBJ, ICRO, (ICOND (I), $i=1,3),(0911(\mathrm{~J}), J=1, N B L O C K)$

$I C R D=I C R O+1$

WRITE $(62,295)$ ISUBJ, ICRO. (ICONO (I.), I=1,3), (XBAR714 (J), J=1, NBLCCK) $I C R D=I C R D+1$

WRITE $(62,295)$ I SUB J, ICRD, (ICOND (I), I = 1,3), (XBAR812(J), J=1,N3LOCK)

$I C R D=I C F D+1$

WRI TE $(62,295)$ I SUR J, ICRD, (ICOND (I), I =1,3), (XRAR911(J),J=1, NRLOCK)

ICRD = ICRD+1

WRITE (62, 295) ISUBJ, ICRD, (ICOND (I), I=1,3), (SD714(J), J=1, NBLOCK)

$I C R D=I C R N+1$

WRITE $(62,295)$ ISUBJ, ICRO, (ICONJ (I),I=1,3), (SD8 $12(\mathrm{~J}), J=1, N B L O C K)$

$I C R D=I C R D+1$

WRITE $(6 \bar{C}, 295)$ ISUBJ, ICRD, (ICOND $(I), I=1,3),(S 0911(\mathrm{~J}), J=1, N B L O C K)$

$I C R D=I C R D+1$

WRITE $(62,295)$ ISUBJ, ICRD, (ICCND (I),I=1,3), (SK714 (J), J=1, NBL OCK)

ICRD = ICRD+1

WRITE (62, 295) I SU3J, ICRD, (ICOND(I), I =1,3), (SK812(J), J=1, NBLOCK)

ICRD = ICR +1

WRITE $(62,295)$ I SUBJ, ICRD, (ICOND (I), I=1,3),(5K911(J),J=1, NEL OCK) $I C R D=I C P O+1$

WPITE $(62,295)$ I SUB J, I CRE, IIC.OND (I), I =1,3), $(K 714(\mathrm{~J}), J=1$, NAL OCK)

$I C R D=I C R D+1$

WRITE (62, 295) ISUBJ, ICRD, (ICONOII),I=1,3), (K812(J),J=1, NALOCK)

ICRD $=1 C R \Pi+1$

WRITE $(62,295)$ ISUBJ,ICRD, $(\operatorname{ICONO}(I), I=1,3),(K 911(\mathrm{~J}), J=1, N B L O C K)$

ICRO = ICFD+ I

WRI IE $(62,295)$ I SUB J, ICRO, (ICOND (I), I=1,3), (R10911( J), J=1,NBLOCK)

$I C P D=I C R D+1$

WPITE (52,295) I SUBJ, ICRC, (ICONDII), I =1,3), (R10812(J),J=1,N3LOCK)

$I C R D=I C F O+1$ 


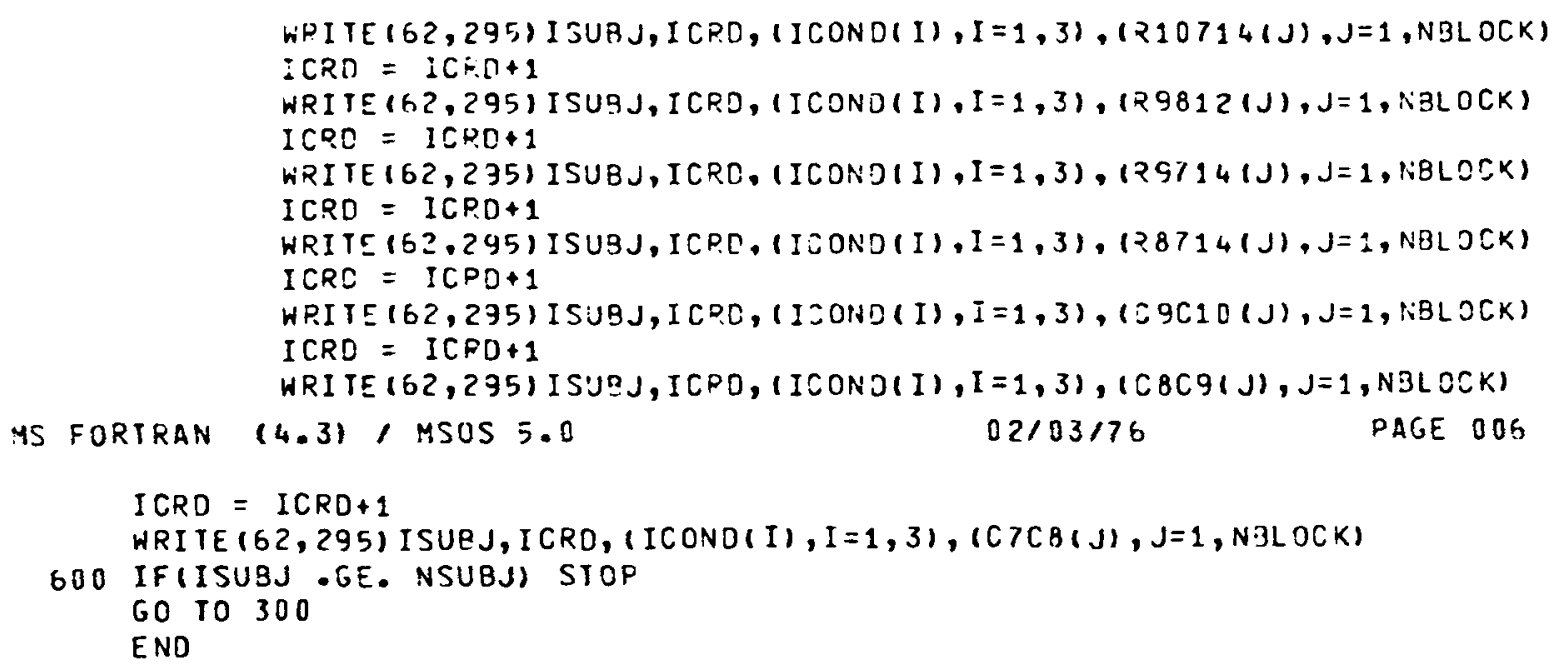

\section{REFERENCES}

Bentty, J., \& Figueron, C. Period analytic algorithms for the estimation of selected spectral properties of short segments of EEG data. Behavior Research Methods \& Instrumentation, 1974, 6, 293-295.

Creutzfeldt, Grunewald, G., Simonova, O., \& Schmitz, H. Changes of the basic rhythms of the EEG during the performance of mental and visuomotor tasks. In C. R. Evans \& T. B. Mulholland (Eds.), Attention in neurophysiology. London: Butterworth, 1969. Pp. 148-168.

DUMermUth, G., \& KELLER, E. EEG spectral analysis by means of fast fourier transform. In $P$. Kellaway \& I. Petersen (Eds.), Automation of clinical electroencephalography. New York: Raven Press, 1973. Pp. 145-159.

Hoovey, Z. B., Heinemann, U., \& Creutzareld, O. D. Inter-hemispheric "synchrony" of alpha waves. $E E G$ Journal, 1972, 32, 337-347.

Richmond, A. E. Calculus for electronics. New York: McGraw-Hill, 1972. P. 413.
Rouse, L. O. On-line period analysis of EEG by time-toamplitude conversion (TAC). Psychophysiology, 1975, 12, 476-479.

Rouse, L. O., Peterson, J., \& Shapiro, G. EEG alpha entrainment reaction within the biofeedback setting and some possible effects on epilepsy. Physiological Psychology, 1975, 3, 113-122.

SAYER, G. The mechanism of auditory evoked EEG responses. Nature, 1974, 247, 481-483.

Sharp, F. H., Smith, G. W., \& Surwillo, W. W. Period analysis of the electroencephalogram with recording of interval histograms of EEG half-wave durations. Psychophysiology, $1975,12,471.475$.

SuRwLllo, W. W. Interval histogram analysis of period of the electroencephalogram in relation to age during growth and development in normal children. Psychophysiology, $1975,12,506-512$.

(Received for publication January 9, 1978; revision accepted January 24, 1978.) 